\title{
Article \\ HCC in the Era of Direct-Acting Antiviral Agents (DAAs): Surgical and Other Curative or Palliative Strategies in the Elderly
}

\author{
Stefania Brozzetti ${ }^{1}$, Marsia Tancredi ${ }^{1}$, Simone Bini ${ }^{2, *}$,, Chiara De Lucia ${ }^{1}$, Jessica Antimi ${ }^{1} \oplus$, \\ Chiara D'Alterio ${ }^{1}{ }^{\mathbb{D}}$, Giuseppe Maria De Sanctis ${ }^{3}$, Caterina Furlan ${ }^{3}$, Vittoria Carolina Malpassuti ${ }^{4}(\mathbb{1}$, \\ Pierleone Lucatelli ${ }^{5}$ (D), Michele Di Martino ${ }^{5}$, Mario Bezzi ${ }^{5}$, Antonio Ciardi ${ }^{6}$ and Rosa Maria Pascale ${ }^{7}$ (i)
}

1 Department of Surgery "Pietro Valdoni", Policlinico Umberto I, University of Rome La Sapienza, 00161 Rome, Italy; stefania.brozzetti@uniroma1.it (S.B.); marsiatancredi.1995@gmail.com (M.T.); chiara.delucia@uniroma1.it (C.D.L.); antimi.1732924@studenti.uniroma1.it (J.A.); dalteriochiara@gmail.com (C.D.)

2 Department of Translational and Precision Medicine, Policlinico Umberto I, University of Rome La Sapienza, 00161 Rome, Italy

3 Department of Tropical and Infectious Diseases, Policlinico Umberto I, University of Rome La Sapienza, 00161 Rome, Italy; giuseppe.desanctis@uniroma1.it (G.M.D.S.); caterina.furlan@uniroma1.it (C.F.)

4 Department of Statistical Sciences, University of Rome La Sapienza, 00161 Rome, Italy; vittoriacarolina.malpassuti@uniroma1.it

check for updates

Citation: Brozzetti, S.; Tancredi, M.; Bini, S.; De Lucia, C.; Antimi, J.; D’Alterio, C.; De Sanctis, G.M.; Furlan, C.; Malpassuti, V.C.; Lucatelli, P.; et al. HCC in the Era of Direct-Acting Antiviral Agents (DAAs): Surgical and Other Curative or Palliative Strategies in the Elderly. Cancers 2021, 13, 3025. https://doi.org/10.3390/ cancers13123025

Academic Editors: Liliana Chemello, Luisa Cavalletto and Erica Villa

Received: 29 April 2021

Accepted: 15 June 2021

Published: 17 June 2021

Publisher's Note: MDPI stays neutral with regard to jurisdictional claims in published maps and institutional affiliations.

Copyright: () 2021 by the authors. Licensee MDPI, Basel, Switzerland. This article is an open access article distributed under the terms and conditions of the Creative Commons Attribution (CC BY) license (https:// creativecommons.org/licenses/by/ $4.0 /)$.
5 Department of Radiological Sciences Policlinico Umberto I, University of Rome La Sapienza, 00161 Rome, Italy; pierleone.lucatelli@gmail.com (P.L.); michele.dimartino@uniroma1.it (M.D.M.); mario.bezzi@uniroma1.it (M.B.)

6 Department of Radiological, Oncological, Pathological Sciences, Policlinico Umberto I, Sapienza University of Rome, 00161 Rome, Italy; antonio.ciardi@uniroma1.it

7 Department of Medical, Surgery and Experimental Sciences, Division of Experimental Pathology and Oncology, University of Sassari, 07100 Sassari, Italy; patsper@uniss.it

* Correspondence: simone.bini@uniroma1.it

Simple Summary: This study investigated HCC onset in a cohort of patients receiving DAA therapy for HCV infection. It highlights that HCC onset after HCV-clearance might show more aggressive behavior and might exclude the patient from curative treatments, such as surgery or radiofrequency ablation. Moreover, HCC may develop in livers with mild to moderate fibrosis, indicating that multiple factors (host immune response, host metabolism, etc.) may play an important role in determining the cancer onset or its recurrence after $\mathrm{HCV}$ eradication. It is crucial to classify long-term chronically infected patients as at high risk for HCC development and to implement strict follow-up for them after eradication.

Abstract: Hepatocellular carcinoma (HCC) accounts for $75-85 \%$ of primary liver malignancies, and elderlies have the highest incidence rates. Direct-acting antiviral agents (DAAs) have shown satisfying results in terms of HCV sustained viral response (SVR). However, data regarding HCC risk post-DAA-SVR is still conflicting. This study aims to consider HCC onset in moderate underlying liver disease. We conducted a retrospective study on 227 chronically infected patients (cHCV), treated with DAAs. Patients were divided into three groups: "de novo occurrent HCC", "recurrent HCC", and "without HCC". Fifty-six patients aged <65 years (yDAA) were studied separately. HCC patients aged $\geq 65$ years (DAA-HCC) were compared to a historical group of 100 elderly HCC patients, treated with peginterferon (Peg-IFN) \pm ribavirin antiviral agents, non-SVR (hHCC). The HCC prevalence in DAA patients was $32.75 \%$ : "de novo occurrent" $18.13 \%$ and "recurrent" $14.62 \%$, despite $42.85 \%$ of them having no fibrosis to mild or moderate fibrosis (F0-F1-F2). yDAA showed 5.36\% "de novo occurrent" HCC. Curative procedure rates were compared between DAA-HCC and hHCC at the first and at recurrent presentation $(22(39.29 \%)$ vs. $72(72 \%) ; 17(30.36 \%)$ vs. $70(70 \%)$, respectively $(p<0.001))$. No significant difference was found in 3-year OS ( $p=0.6)$. However, in cause-specific mortality analysis, HCC-related death was higher in the DAA-treated group, whereas cirrhosis-related death was more common in the historical group $(p=0.0288)$, considering together the two causes of death. A more accurate patient stratification according to multifactorial and new diagnostic investigations identifying HCC risk might allow an improvement in management and access to curative therapies. 
Keywords: hepatocellular carcinoma; hepatitis C virus; HCV; HCC; HCC recurrence; DAA; surgery; locoregional therapy

\section{Introduction}

Hepatocellular carcinoma (HCC) is the fifth most common cancer in men and the seventh most common cancer in women. It is also the second leading cause of cancer death worldwide [1,2].

More than $70 \%$ of cases are due to chronic hepatitis related to hepatitis B virus (HBV) in the Asia Pacific region and sub-Saharan Africa and to hepatitis C virus (HCV) in Western countries [3-5].

The annual risk of developing HCC is about $3-3.5 \%$ in the general population in advanced liver disease [6]. Its prevalence, morbidity, and mortality, associated with low rates of diagnosis and treatment, have become one of the major public health challenges.

Antiviral agents that eliminate hepatitis $C$ virus infection may prevent or reduce HCC risk in the liver with advanced fibrosis or cirrhosis. Until 2011, chronic hepatitis $C$ therapy was limited to the combination of pegylated interferon ( $\alpha 2 \mathrm{a}$ or $\alpha 2 \mathrm{~b})$ and ribavirin with a $30-75 \%$ eradication chance, depending on the viral genotype, lower for genotype $1[7,8]$. The introduction of interferon-free direct-acting antiviral (DAA) treatments, with the initial approval of sofosbuvir in December 2013, has changed the landscape of HCV therapy, and rates of sustained viral response (SVR) of more than $95 \%$ have been reported. These new drugs are different in terms of efficacy, side effects, and genotypic drug resistance. In 2015, over 100 million patients, the majority with liver cirrhosis, were treated with new antiviral drugs $[9,10]$.

In Italy, F0-F1 patients with extrahepatic diseases (type 2 diabetes, kidney damage, immune-mediated manifestations, cardiovascular disease, obesity) have been included in the AIFA (Italian Medicines Agency) guidelines for DAA therapy since 2017 [11].

In this new scenario, the incidence of HCV infection, the evolution in cirrhosis, and the incidence of HCC should have decreased dramatically over a few decades. Instead, unexpected data from recent studies showed that SVR does not eliminate the risk of developing HCC post-DAA. Other studies raised the suspicion that DAAs might promote an early HCC occurrence (de novo) or recurrence in cured HCC patients [12-15]. This study aims to show the impact of HCC after new antiviral therapies in our cohort of patients affected by different features of liver damage and to compare treatments and outcomes with a historical group of HCC patients. Finally, the data gained from the study are discussed to clarify the suspicion of a vulnerability in HCC onset as a result of multiple involved pathways emerging.

\section{Methods}

\subsection{Study Setting and Participants}

Retrospective data of 227 patients treated with DAAs from October 2015 to December 2019 were collected and analyzed. We included adult patients ( $>18$ years of age) with cHCV infection. HCV infection was confirmed with quantitative real-time polymerase chain reaction (RT-qPCR) and genotyping/subgenotyping was carried out. Exclusion criteria were HIV / HBV coinfection, alcohol abuse, not achieving sustained viral response, therapy drop-out, liver transplantation, and a follow-up of less than 12 months. A flow chart of the patients' enrollment is shown in Figure 1. 


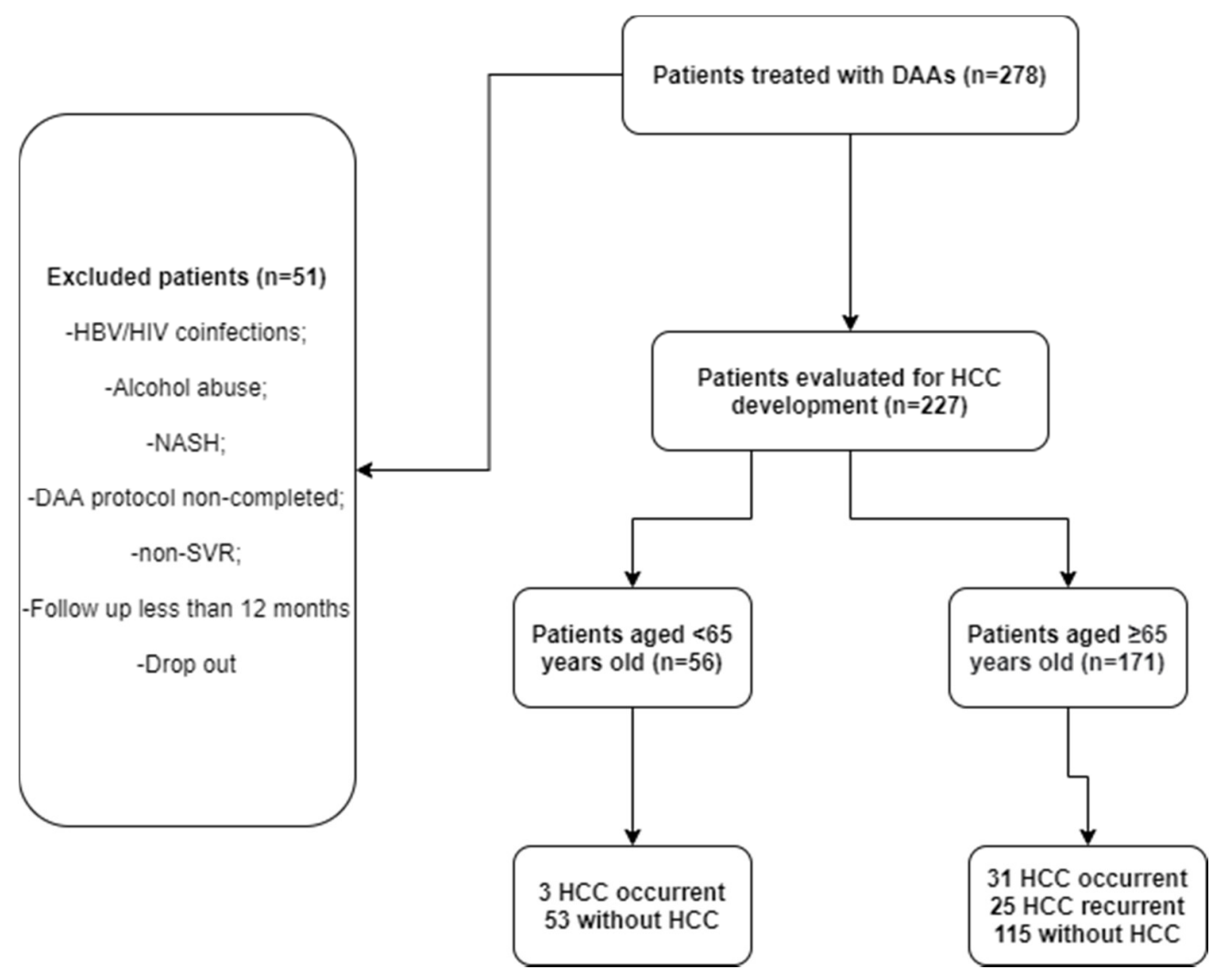

Figure 1. Flow chart of patient selection criteria in this retrospective study.

At baseline, data on clinical characteristics and parameters, namely age, sex, anthropometric parameters, and comorbidities (ASA score), and extrahepatic diseases (type 2 diabetes, kidney damage, immune-mediated manifestations, cardiovascular disease, obesity) were collected.

Liver damage was assessed according to the Child-Turcotte-Pugh score (CTP); the Model for End-Stage Liver Disease (MELD) score and the liver stiffness scales (METAVIR scale, Fibroscan values, F4 value). Platelet count, splenomegaly, varices, and serum alphafetoprotein (AFP) levels pre-DAA were also considered.

HCCs were staged according to the Barcelona Clinic Liver Cancer (BCLC) staging system considering lesion number, size, and localization. DAA treatment regimens were recorded for all patients.

Liver imaging study (ultrasound (US), computed tomography/magnetic resonance (CT/MRI)) and serum alpha-fetoprotein (AFP) levels were requested to rule out HCC before starting antiviral therapy.

The liver fibrosis stage was assessed by histological exam in the surgical specimen or by external/intraoperative biopsy (METAVIR F0-F4) by noninvasive methods including transient elastography and laboratory determinations (FIB-4). Elastography, analyzed by the Fibroscan (kPa value), was categorized according to international recommendations. Cut-off values of 10 and $12.5 \mathrm{kPa}$ were considered for F3 and F4, respectively. The FIB-4 was calculated using the following formula: (aspartate aminotransferase (AST; U $/ \mathrm{L}) \times$ age (years)) $/$ (platelet count $\left(10^{9} / \mathrm{L}\right) \times$ alanine aminotransferase (ALT; $\mathrm{U} / \mathrm{L})^{1 / 2}$ ). A cut-off value of 3.25 was considered an index of severe fibrosis $[16,17]$.

The severity of cirrhosis was also defined by US, CT, and MRI images according to hepatic size and profile, nodularity, portal flow and diameter, esophageal varices, and splenomegaly [18]. Steatosis was detected by US/MRI or by liver biopsy or surgical sampling. The DAA regimen used was based on international guidelines [19]. The efficacy of antiviral therapy, referred to as SVR, was defined as undetectable HCV RNA $(<15 \mathrm{IU} / \mathrm{mL})$ tested at the end of DAA protocol, at 24 weeks, and at 1 year. Surveillance with AFP 
levels and US were performed at 6 and then every 12 months after DAA therapy. Any new liver nodule ( $\geq 5 \mathrm{~mm}$ ) found on ultrasound was followed up by the US at 3 months and $(\geq 10 \mathrm{~mm})$ by CT scan or MRI with liver-specific contrast medium.

HCC (occurrent or recurrent) was staged according to the BCLC system, and nodules were assessed for size, localization, and number [20,21]. Patients were divided into three groups: HCC-O "de novo occurrent", HCC-R "recurrent", and patients without a history of HCC onset "without HCC". The time from achieving SVR to the onset of HCC was also recorded and assessed. HCC treatment modality was established in a multidisciplinary expert team (hepatologists, surgeons, radiologists, and oncologists) according to the BCLC staging system combined with patient general conditions and liver damage. Surgical resection (SR), radiofrequency (RF) ablation, and liver transplantation (LT) (not available due to the patients' age) were classified as potentially curative therapies, while transcatheter arterial chemoembolization (TACE), intra-arterial radioembolization (IART), and systemic therapy (ST) with different schemes were classified as noncurative treatments [22].

One hundred seventy-one patients (median age of 73 years (IQR: 67-81.)) were selected from this cohort, and those with HCC (HCC-O and HCC-R) after DAA therapy (DAA-HCC) were compared to a historical group of HCC patients (hHCC) (median age of 74.5 years (IQR: 70-79)) treated in a period before the era of DAA therapy with Peg-INF \pm ribavirin, who did not achieve HCV SVR (except 4 patients). Eleven of the included hHCC patients had already undergone curative-specific treatments (10 radiofrequency ablations and 1 surgical resection). In the DAA-treated cohort, patients in the "without $H C C$ " group did not have any previous history of HCC, whereas patients in the "HCC-R" group received curative treatment for the previous HCC lesion: 16 patients underwent surgical resection and 9 patients received radiofrequency ablation. Characteristics of the patients, tumors, modality of treatment, overall survival (OS), and cause-specific mortality were analyzed. Fifty-six DAA patients under 65 years of age were analyzed separately (Table S1).

\subsection{Statistical Analysis}

According to the test of normality (Shapiro-Wilk test), mean (+/-standard deviation (SD)) or median (interquartile range (IQR)) were calculated for normally and non-normally distributed continuous data, respectively.

The continuous variables were assessed using the Student's $t$-test for parametric variables or the Mann-Whitney $U$ test for nonparametric variables.

Categorical variables were compared using the chi-square test or Fisher's exact test.

Kaplan-Meier curves were generated to compare time from SVR attainment to diagnosis of HCC and HCC-free survival by treatment regimen among different groups.

A $p$-value $<0.05$ was considered statistically significant.

The statistical analysis was carried out using the R software (version 3.6.1).

\section{Results}

The cohort of elderly patients treated with DAA therapy included 139 men and 88 women (ratio 1.6:1) with a median age of 68 years (IQR: 65-78). All patients achieved SVR. While 138 patients had been previously treated with interferon (Peg-INF \pm ribavirin)based therapies, 89 patients had never received antiviral drugs before (naive). The median follow-up after DAA treatment was 45 months (IQR: 24-52).

After DAA therapy, HCC prevalence was higher in the group of elderly patients: 56 (32.75\%) out of 171, of which 31 (18.13\%) had "de novo HCC occurrence" and $25(14.62 \%)$ had "recurrent HCC". However, only 3 cases of HCC occurred in the population aged $<65$ years (Table S1). In the "without HCC" group, patients did not have any history of HCC before DAA therapy. Male sex in the elderly was more frequently associated with HCC development: 25 males vs. 6 females in HCC-O group, 18 males vs. 7 females in HCC-R group $(p<0.001)$, and 67 males vs. 33 females in the hHCC group $(p<0.001)$. Clinical, laboratory, and instrumental variables of 171 DAA-treated elderly patients are 
reported in Table 1. Chronic viral hepatitis has been the object of the most extensive efforts in grading and staging liver damage, stimulated by the advent of new antiviral therapies. According to the international guidelines, we combined invasive and noninvasive methods and biological tests to evaluate liver function and grade of fibrosis. There was no significant difference among the groups of DAA patients for the Child-Turcotte-Pugh (CTP) score, MELD score, METAVIR, FIB-4, liver stiffness, or platelet count. In HCC-O and HCC-R groups, a total of 53 patients $(94.64 \%)$ had a CTP score A (5.6), 3 patients $(5.36 \%)$ had a CTP score B $(7,8,9)$, and no patients had a CTP score C. F0-F2 liver fibrosis was found in $40.53 \%$ of all DAA-treated elderly patients and in $42.86 \%$ of DAA-HCC $(32.14 \%$ F0F1). Noninvasive methods for parenchyma evaluation showed medians above the cut-off for the predictive value for severe fibrosis in HHC-O or HCC-R groups. The IQR also included values under the cut-off, due to the wide presence of patients showing mild fibrosis (Table 1). No patients were found to develop severe steatosis or steatohepatitis. $\mathrm{HCV}$ genotype was not associated with differences in HCC rates among the three groups. AFP serum values pre-DAA treatment were commonly higher in HHC-O and HCC-R groups in comparison with the "without HCC" group (4.5 (IQR: 2.8-9.32) vs. 4.6 (IQR: $3-6.4)$ vs. 2.4 (IQR: 1.12-4.11), $p<0.001$ ); however, AFP level was never markedly elevated.

Table 1. Characteristics of the elderly population studied.

\begin{tabular}{|c|c|c|c|c|c|}
\hline Variable & $\begin{array}{l}\text { HCC-O } \\
(n=31)\end{array}$ & $\begin{array}{l}\text { HCC-R } \\
(n=25)\end{array}$ & $\begin{array}{l}\text { Without HCC } \\
\quad(n=115)\end{array}$ & Total $(n=171)$ & $p$ Value \\
\hline Age, years, median (IQR) & $73(67-81.50)$ & $69(67-75)$ & $74(67-80)$ & $73(67-80)$ & 0.315 \\
\hline Male, $n(\%)$ & $25(80.65)$ & $18(72)$ & $54(46.96)$ & $97(56.73)$ & \multirow{2}{*}{$<0.001$} \\
\hline Female, $n(\%)$ & $6(19.35)$ & $7(28)$ & $61(53.04)$ & $74(43.27)$ & \\
\hline $\mathrm{BMI}, \mathrm{kg} / \mathrm{m}^{2}$, median (IQR) & $26.10(25.5-26.5)$ & $26.10(26-26.5)$ & $26(25.5-26.8)$ & $26(25.5-26.7)$ & 0.672 \\
\hline \multicolumn{6}{|l|}{ Comorbidities, $n(\%)$} \\
\hline Obesity & $2(6.45)$ & $1(4)$ & $16(13.91)$ & $19(11.11)$ & 0.373 \\
\hline Diabetes mellitus 2 & $7(22.58)$ & $4(16)$ & $13(11.3)$ & $24(14.04)$ & 0.239 \\
\hline Metabolic syndrome & $5(16.13)$ & $3(12)$ & $12(10.43)$ & $20(11.17)$ & 0.592 \\
\hline Chronic obstructive pulmonary diseases & $3(9.68)$ & $2(8)$ & $4(3.48)$ & $9(5.26)$ & 0.203 \\
\hline Cardiovascular diseases & $5(16.13)$ & $4(16)$ & $0(0)$ & $9(5.26)$ & $<0.001$ \\
\hline Kidney failure & $4(12.9)$ & $3(12)$ & $17(14.78)$ & $24(14.04)$ & 1 \\
\hline Hypertension & $11(35.48)$ & $7(28)$ & $27(23.48)$ & $45(26.32)$ & 0.372 \\
\hline Hemoglobin disorders & $2(6.45)$ & $2(8)$ & $5(4.35)$ & $9(5.26)$ & 0.666 \\
\hline Autoimmune diseases & $3(9.68)$ & $2(8)$ & $2(1.74)$ & $7(4.09)$ & 0.053 \\
\hline ASA, $n(\%)$ & & & & & 0.336 \\
\hline I & $21(67.74)$ & $13(52)$ & $60(52.17)$ & $94(54.97)$ & \\
\hline II & $9(29.03)$ & $11(44)$ & $55(47.83)$ & $75(43.86)$ & \\
\hline III & $1(3.23)$ & $1(4)$ & $0(0)$ & $2(1.17)$ & \\
\hline HCV Genotype, $n(\%)$ & & & & & 0.8693 \\
\hline 1 & $19(61.29)$ & $17(68)$ & $73(63.48)$ & $109(63.74)$ & \\
\hline Non-1 & $12(38.71)$ & $8(32)$ & $42(36.52)$ & $62(36.26)$ & \\
\hline \multicolumn{6}{|l|}{ Child-Turcotte-Pugh score, $n(\%)$} \\
\hline $\mathrm{A}$ & $29(93.55)$ & & $108(93.91)$ & $161(94.15)$ & \\
\hline $\mathrm{B}$ & $2(6.45)$ & & $7(6.09)$ & $10(5.85)$ & 1 \\
\hline $\mathrm{C}$ & $0(0)$ & & $0(0)$ & $0(0)$ & \\
\hline MELD, median (IQR) & $9(7-11.5)$ & $9(7-11)$ & $8(7-9)$ & $8(7-10)$ & 0.095 \\
\hline \multicolumn{6}{|l|}{ METAVIR, $n(\%)$} \\
\hline F0-1 & $7(22.58)$ & $11(44)$ & $32(27.83)$ & $50(29.24)$ & \multirow{4}{*}{0.385} \\
\hline $\mathrm{F} 2$ & $4(12.90)$ & $2(8)$ & 17 (14.78) & $23(13.45)$ & \\
\hline F3 & $5(16.13)$ & $4(16)$ & $10(8.70)$ & $19(11.11)$ & \\
\hline $\mathrm{F} 4$ & $15(48.39)$ & $8(32)$ & $56(48.70)$ & $79(46.20)$ & \\
\hline FIB-4, median (IQR) & $4(2.34-5.83)$ & $4.19(2.95-6)$ & $3.21(1.74-6.17)$ & $3.56(1.95-6.08)$ & 0.246 \\
\hline Stiffness, median (IQR) & $12(8.63-16.8)$ & $10.4(6-14)$ & $12.5(6.8-18.6)$ & $11.8(6.4-17.05)$ & 0.218 \\
\hline Steatosis & $2(6.45)$ & $2(8)$ & $26(22.61)$ & $30(17.54)$ & 0.055 \\
\hline Platelets, $10^{9} / \mathrm{L}$, median (Range) & $147(42-362)$ & $153(32-464)$ & $143(29-350)$ & $147(29-464)$ & 0.899 \\
\hline
\end{tabular}


Table 1. Cont.

\begin{tabular}{|c|c|c|c|c|c|}
\hline Variable & $\begin{array}{l}\text { HCC-O } \\
(n=31)\end{array}$ & $\begin{array}{l}\text { HCC-R } \\
(n=25)\end{array}$ & $\begin{array}{l}\text { Without HCC } \\
\qquad(n=115)\end{array}$ & Total $(n=171)$ & $p$ Value \\
\hline \multicolumn{6}{|l|}{ Varices, $n(\%)$} \\
\hline 0 & $22(70.97)$ & $12(48)$ & $84(73.04)$ & $118(69.01)$ & \multirow{3}{*}{0.072} \\
\hline 1 & $8(25.81)$ & $13(52)$ & $27(23.48)$ & $48(28.07)$ & \\
\hline 2 & $1(3.23)$ & $0(0)$ & $4(3.48)$ & $5(2.92)$ & \\
\hline AFP pre-DAA, UI/L, median (IQR) & $4.5(2.8-9.32)$ & $4.6(3-6.4)$ & $2.4(1.12-4.11)$ & $3(1.45-5.05)$ & $<0.001$ \\
\hline DAA, $n(\%)$ & & & & & 0.9164 \\
\hline SOF-Based & $26(83.87)$ & $20(80)$ & $92(80)$ & $138(80.70)$ & \\
\hline Non-SOF-Based & $5(16.13)$ & $5(20)$ & $23(20)$ & $33(19.30)$ & \\
\hline
\end{tabular}

SOF, sofosbuvir; $p$-value was calculated between HCC-O, HCC-R, and cases without HCC.

The median latency time from SVR to HCC detection was 14 months (IQR: 7.5-23.5) in HCC-O group vs. 13 months (IQR: 5-22) in HCC-R group ( $p=0.287$ ). Tumor characteristics and treatments are shown in Table 2. According to the BCLC system, 26 patients $(46.4 \%)$ were in stage $A, 22(39.3 \%)$ were in stage $B$, and $8(14.3 \%)$ were in stage $C$, without significant differences between HCC-O and HCC-R groups.

Table 2. Main characteristics of de novo occurrent and recurrent HCCs.

\begin{tabular}{|c|c|c|c|c|}
\hline Variable & HCC-O & HCC-R & TOTAL & $p$ Value \\
\hline Age, years, median (IQR) & $73(67-81.50)$ & $69(67-75)$ & $70(66.75-80)$ & 0.271 \\
\hline Male, $n(\%)$ & $25(80.65)$ & $18(72)$ & $43(76.79)$ & \multirow[b]{2}{*}{0.657} \\
\hline Female, $n(\%)$ & $6(19.35)$ & $7(28)$ & $13(23.21)$ & \\
\hline BMI, kg/m2, median (IQR) & $26.10(25.5-26.5)$ & $26.10(26-26.5)$ & $26.10(25.65-26.5)$ & 0.409 \\
\hline HCV Genotype, $n(\%)$ & & & & 0.81 \\
\hline 1 & $19(61.29)$ & $17(68)$ & $36(64.29)$ & \\
\hline Non-1 & $12(38.71)$ & $8(32)$ & $20(35.71)$ & \\
\hline DAA, $n(\%)$ & & & & 0.738 \\
\hline SOF-Based & $26(83.87)$ & $20(80)$ & $46(82.14)$ & \\
\hline Non-SOF-Based & $5(16.13)$ & $5(20)$ & $10(17.86)$ & \\
\hline Onset from SVR (months), median (IQR), (Range) & $\begin{array}{c}14(7.5-23.5) \\
(3-57)\end{array}$ & $\begin{array}{c}13(5-22) \\
(1-41)\end{array}$ & $\begin{array}{c}14(7-23.25) \\
(1-57)\end{array}$ & 0.287 \\
\hline Numbers of nodules, $n(\%)$ & & & & 0.631 \\
\hline 1 & $11(35.48)$ & $12(48)$ & $23(41.07)$ & \\
\hline 2 & $6(19.35)$ & $3(12)$ & $9(16.07)$ & \\
\hline 3 & $14(45.16)$ & $10(40)$ & $24(42.86)$ & \\
\hline HCC size $(\mathrm{cm})$, median, (Range) & $2.8(1-8)$ & $2.2(0.8-5.1)$ & $2.6(0.8-8)$ & 0.225 \\
\hline Site, $n(\%)$ & & & & 0.958 \\
\hline Right liver & $21(67.74)$ & $18(72)$ & $39(69.64)$ & \\
\hline Left liver & $10(32.26)$ & $7(28)$ & $17(30.36)$ & \\
\hline BCLC STAGE, $n(\%)$ & & & & 0.874 \\
\hline $0-\mathrm{A}$ & $13(41.935)$ & $12(48)$ & $25(44.64)$ & \\
\hline $\mathrm{B}$ & $13(41.935)$ & $9(36)$ & $22(39.29)$ & \\
\hline $\mathrm{C}$ & $5(16.13)$ & $4(16)$ & $9(16.07)$ & \\
\hline I Treatment, $n(\%)$ & & & & 1 \\
\hline Curative treatments & $12(38.71)$ & $10(40)$ & $22(39.29)$ & \\
\hline Palliative treatments & $19(61.29)$ & $15(60)$ & $34(60.71)$ & \\
\hline II Treatments, $n(\%)$ & $8(25.81)$ & $9(36)$ & $17(30.36)$ & 0.594 \\
\hline Curative treatments & $2(25)$ & $2(22.2)$ & $4(23.53)$ & \\
\hline Palliative treatments & $6(75)$ & $7(77.8)$ & $13(76.47)$ & \\
\hline III treatments, $n(\%)$ & $2(6.45)$ & $3(12)$ & $5(8.93)$ & 0.647 \\
\hline Curative treatments & $0(0)$ & $1(33.33)$ & $1(20)$ & \\
\hline Palliative treatments & $2(100)$ & $2(66.67)$ & $4(80)$ & \\
\hline
\end{tabular}


Tumor characteristics and treatment allocation to each stage between selected patients (DAA-HCC) and hHCC group are summarized in Table 3. hHCC patients had the advantage of a larger combination of curative treatments, resection and RF ablation, compared to DAA-HCC (72 (72.0\%) vs. $22(39.29 \%)$ and $70(70 \%)$ vs. $17(30.36 \%)$ at first and second tumor presentation, respectively; $p<0.001$ ). The presence of more multinodular forms or larger HCC dimensions is reflected in the data found in the DAA HCC group. This evidence was one of the reasons that prompted us to start our study (Figures 2 and 3).

Table 3. Comparison between DAA-HCC and h-HCC groups.

\begin{tabular}{|c|c|c|c|}
\hline Variable & DAA-HCC $(n=56)$ & h-HCC $(n=100)$ & $p$ Value \\
\hline Age, years, median (IQR) & $70(66.75-80)$ & $74.50(70-79)$ & 0.064 \\
\hline Male, $n(\%)$ & $43(76.69)$ & $67(67)$ & \multirow{2}{*}{0.270} \\
\hline Female, $n(\%)$ & $13(23.21)$ & $33(33)$ & \\
\hline BMI, Kg/m2, median (IQR) & $26.10(25.65-26.5)$ & $27(26-28)$ & $<0.001$ \\
\hline \multicolumn{4}{|l|}{ Comorbidities, $n(\%)$} \\
\hline Hypertension & $7(12.5)$ & $71(71)$ & $<0.001$ \\
\hline Cardiovascular diseases & $5(8.93)$ & $19(19)$ & 0.149 \\
\hline Pulmonary diseases & $5(8.93)$ & $41(41)$ & $<0.001$ \\
\hline Kidney failure & $9(16.07)$ & $1(1)$ & $<0.001$ \\
\hline Diabetes mellitus 2 & $11(19.64)$ & $20(20)$ & 1 \\
\hline Metabolic syndrome & $8(14.26)$ & $2(2)$ & 0.004 \\
\hline Malnutrition & $0(0)$ & $3(3)$ & 0.553 \\
\hline Characteristics of nodules & & & 0.035 \\
\hline Single & $23(41.07)$ & $60(60)$ & \\
\hline Multiple & $33(58.93)$ & $40(40)$ & \\
\hline HCC size $(\mathrm{cm})$, median, (Range) & $2.6(0.8-8)$ & $2.65(1-12.3)$ & 0.629 \\
\hline Site, $n(\%)$ & & & 0.433 \\
\hline Right liver & $39(69.64)$ & $62(62)$ & \\
\hline Left liver & $17(30.36)$ & $38(38)$ & \\
\hline I Treatment, $n(\%)$ & & & $<0.001$ \\
\hline Curative treatments & $22(39.29)$ & $72(72)$ & \\
\hline Palliative treatments & $34(60.71)$ & $28(28)$ & \\
\hline II treatment, $n(\%)$ & $17(30.36)$ & $70(70)$ & $<0.001$ \\
\hline Curative treatments & $4(23.53)$ & $40(57.14)$ & 0.027 \\
\hline Palliative treatments & $13(76.47)$ & $30(42.86)$ & \\
\hline $\begin{array}{c}\text { 3-year OS, survival \% } \\
\text { (IC 95\%) }\end{array}$ & $\begin{array}{c}76.02 \\
(64.90-89.04)\end{array}$ & $\begin{array}{c}88.93 \\
(82.96-95.32)\end{array}$ & 0.6 \\
\hline Death, $n(\%)$ & $13(23.21)$ & $52(52)$ & 0.008 \\
\hline \multicolumn{4}{|l|}{ Cause of death, $n(\%)$} \\
\hline $\mathrm{HCC}$ & $7(53.85)$ & $13(25)$ & 0.089 \\
\hline Liver disease/Cirrhosis & $2(15.38)$ & $24(46.15)$ & 0.059 \\
\hline Other & $4(30.77)$ & $15(28.85)$ & 1 \\
\hline HCC vs. Liver disease/Cirrhosis, $n(\%)$ & & & 0.0288 \\
\hline HCC & $7(77.78)$ & $13(35.14)$ & \\
\hline Liver disease/Cirrhosis & $2(22.22)$ & $24(64.86)$ & \\
\hline
\end{tabular}




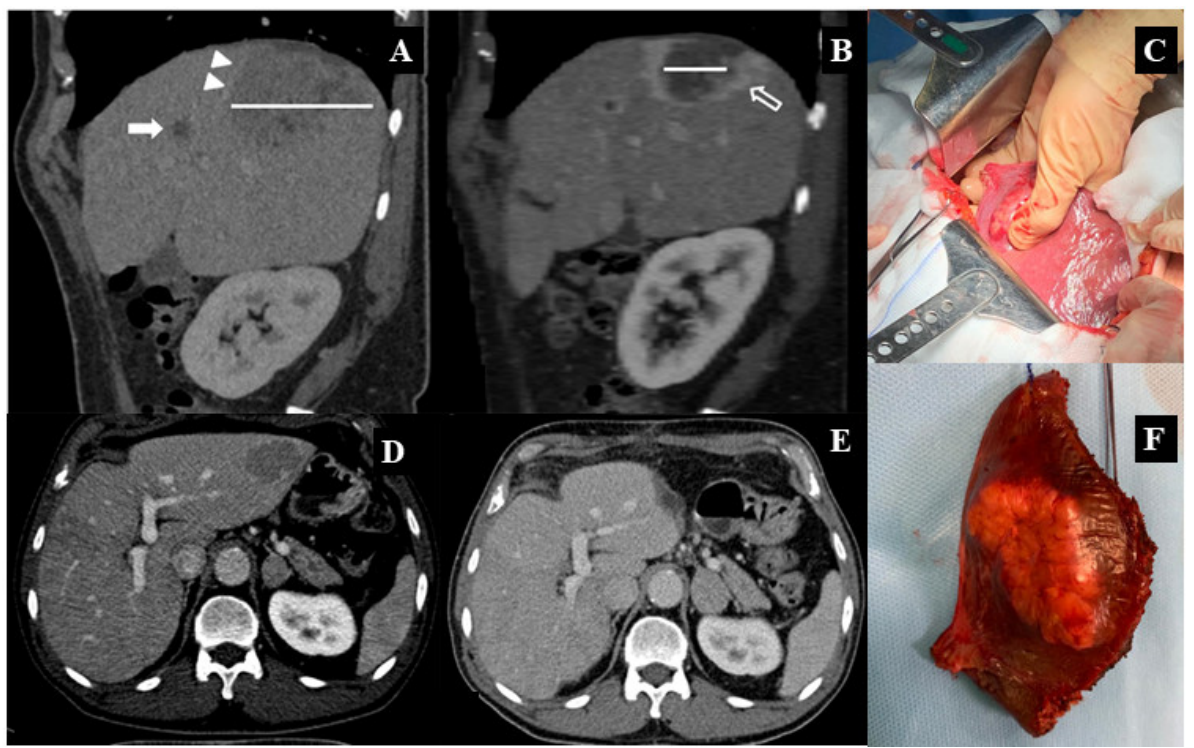

Figure 2. Intraoperative images compared to relative CT scans for one DAA-treated patient. (A) Sagittal reconstructed CT image during the delayed phase shows the huge HCC lesion in liver segment VII (9 cm: white line) with infiltration of right hepatic vein (arrowheads) and the tiny satellite nodule in the $\mathrm{VIII}^{\circ}$ segment. (B) After radioembolization (SIRT), both lesions present central necrotic area and a fibrotic peripheral rim. The bigger lesion is also reduced in size (white line). (D) Axial CT image during the delayed phase shows another HCC lesion across the liver segments II $^{\circ}$ and $\mathrm{III}^{\circ}$ in a noncirrhotic liver. (C) Intraoperative view. (F) Surgical specimen. (E) After surgery, a small fluid collection is appreciable along the resection margin, without any sign of HCC recurrence.

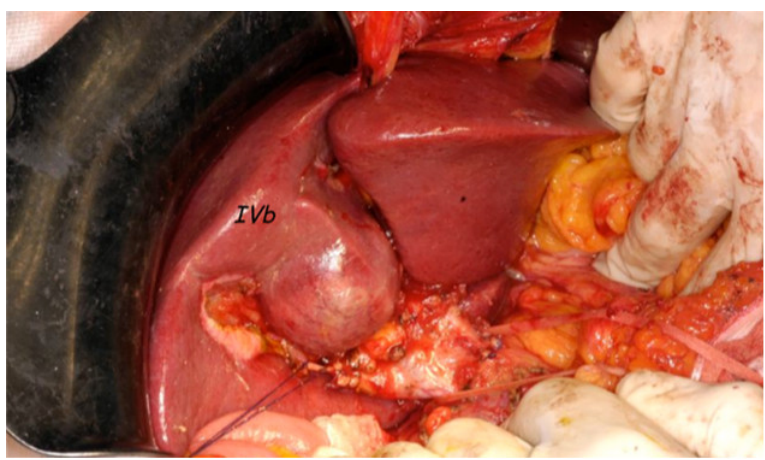

Figure 3. Intraoperative image of one IFN-treated patient. The HCC lesion in a noncirrhotic liver can be observed in segment IV.

Pathohistological diagnosis of resected/biopsied tumors resulted as "trabecular type", except one in the hHCC group that resulted as combined "hepato-cholangiocarcinoma". Morphological staging according to TNM classification, including resection margin assessment and grading, provided uniform data and similarly staged lesions among groups of resected patients.

In December 2020, none of the DAA-HCC patients had completed a five-year followup. The 3-year OS was $76.02 \%$ (IC 95\%: 64.90-89.04) in DAA-HCC vs. $88.93 \%$ (IC 95\%: 82.96-95.32) in h-HCC group (Table 3) (Figure 4). Cause-specific mortality rates are reported in Table 3. We found statistically significant different rates in HCC $(7(53.85 \%)$ vs. $13(25 \%))$ and cirrhosis $(2(15.38 \%)$ vs. $24(46.15 \%))$ between DAA-HCC and h-HCC group $(p=0.0288)$, considering only these two causes of death. Moreover, from December 2020, the end date of our retrospective study, to April 2021, three other elderly patients analyzed in the "without HCC" group developed HCC. The clinical characteristics of 56 patients less than 65 years old are summarized in Table S1. Only three patients developed HCC, and one liver 
transplantation (LT), one liver resection, and one transcatheter arterial chemoembolization

(TACE) for a multifocal disease were administered.

\section{Overall Survival}

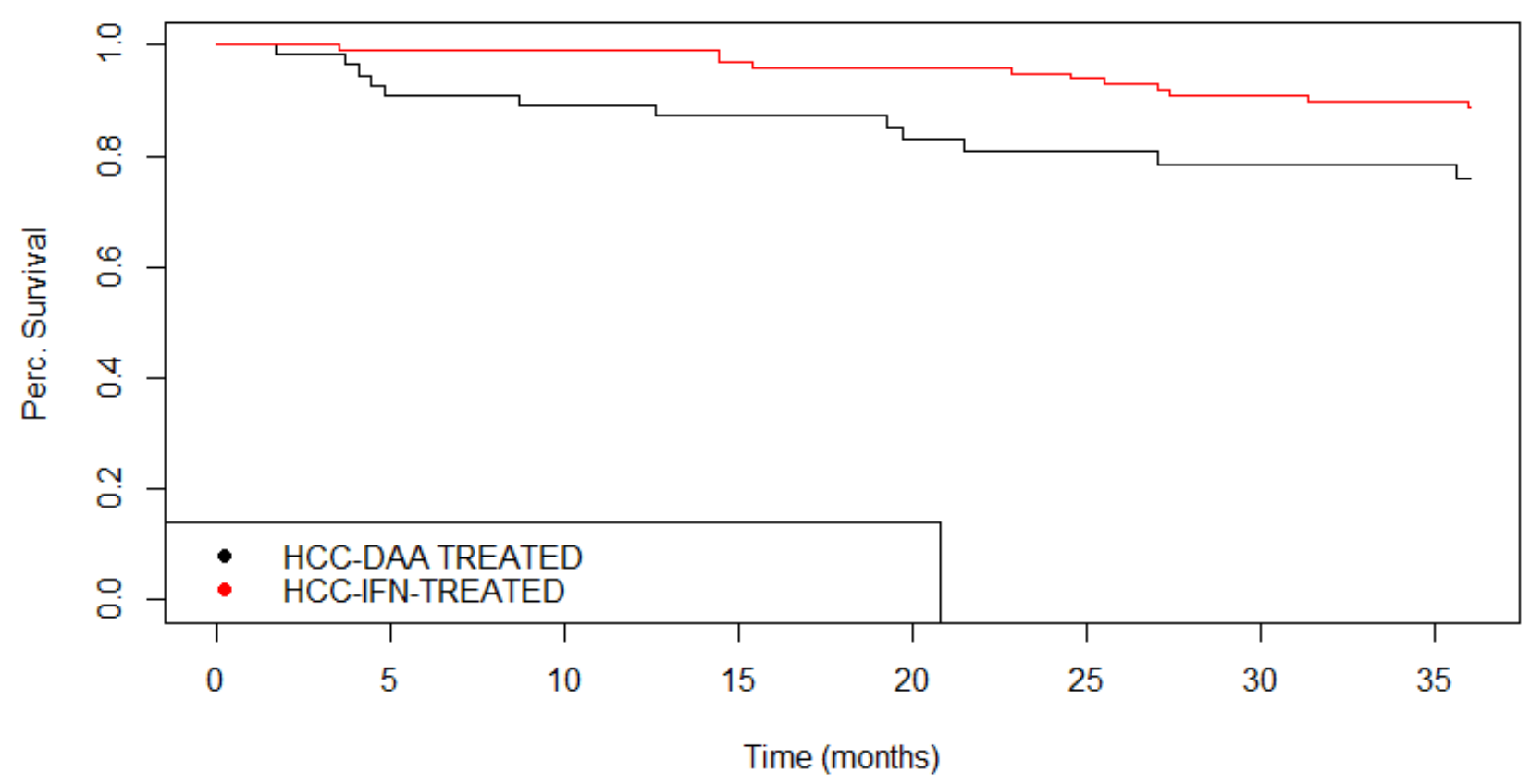

Figure 4. Kaplan-Meier 3-year overall survival in DAA-HCC group vs. hHCC group. Kaplan-Meier analysis of patients' overall survival in historical IFN-treated group (non SVR) compared with overall survival of patients in DAA-treated group.

\section{Discussion}

Hepatitis $\mathrm{C}$ virus (HCV) infection is the main leading etiology of hepatocellular carcinoma in Europe, North America, and Japan. Emerging risk factors for HCC development such as NASH, type 2 diabetes mellitus, and obesity may determine a synergistic or an independent risk [23].

HCV antiviral treatment with IFN-ribavirin therapy produced an SVR in 30-75\% of patients with significant differences according to genotypes (with lower effect in type $1 \mathrm{HCV}$ with a higher level of viremia) $[7,8]$. Difficult tolerability for the severity of side effects and the length of treatment (24-48 weeks) led to low adherence. Infection relapse following an initial sustained virological response was common, leading to therapeutic failure. On the other hand, first and second generations of direct-acting antiviral agents (DAAs) proved to be safe, well-tolerated, of short and easy administration, and highly effective in the eradication of HCV (more than $95 \%$ of cases) $[9,10]$.

However, interferon (IFN)-mediated HCV eradication reduces but does not eliminate the risk of HCC once cirrhosis has been established; in the same conditions, DAA therapy may also not eliminate the risk of HCC. Despite HCV clearance and improved liver function, the process induced by chronic $\mathrm{HCV}$ infection in patients over 20-40 years old, characterized by chronic hepatic inflammation and progressive liver fibrosis, determines the initiation of neoplastic transformation by irreversible somatic genetic or epigenetic alterations that establish the mechanism of HCC development that is not modified by DAA treatment [24-26]. Indeed, we observed an increase in HCC-related mortality and a decrease in cirrhosis-related mortality in the DAA-treated patients as compared to the historical IFN-treated group.

High fibrosis grade is also significantly associated with an elevated risk of HCC onset in patients that cleared HCV infection. Conti et al., in an observational study enrolling 34 cirrhotic patients who received DAA treatment, reported a 3.16\% liver cancer rate, almost the same as in untreated chronically infected patients [13]. Surprisingly, the recurrence rate 
in a population with HCC cured by ablation or resection followed by HCV elimination was higher than that of the untreated population, $28.81 \%$ vs. $20 \%$ [13]. In a similar study, the research group of Reig et al. confirmed an incidence of $27.6 \%$ of HCC recurrence in patients completing the DAA treatment with an SVR [12]. Additionally, Cardoso et al. reported an HCC incidence of $7.4 \%$ in the first year after SVR from DAA treatment, higher than the previously reported incidence rate for IFN regimens $(1.2-1.4 \%)[27,28]$. Indeed, some other multicentric studies did not share a higher rate of HCC occurrence or recurrence in DAA treatment as compared to IFN-treated patients or untreated controls $[29,30]$. We observed increased rates of both HCC occurrence and recurrence in our DAA-treated elderly patients (18.13\% and $14.62 \%$, respectively) as compared to HCC occurrence and recurrence rates observed in untreated patients that range from 5 to $10 \%$ [31].

The vast majority of published studies missed focusing on the correlation between tumor characteristics, stage, and treatment decisions after DAA therapy compared to HCC in IFN-treated or untreated controls. Despite the availability of highly effective direct-acting antiviral agents, the morbidity and incidence of liver-related complications of $\mathrm{HCV}$, including HCC, is likely to persist. The endpoint of DAA therapy is to cure HCV infection and to prevent the HCV-related liver and extrahepatic complications including advancement and decompensation of liver cirrhosis, HCC development, and HCV-related autoimmune diseases [32,33].

Our cohort of DAA-treated patients showed a higher incidence of de novo or recurrent HCC at median 14 and 13 months, respectively. In some cases, HCC onset was observed even after 5 years. Therefore, HCC surveillance in SVR responders should be maintained for at least 5 years, particularly in long-lasting HCV infection. Liver tumors after DAA often showed more aggressive behavior, were larger in size, and were more often multifocal than the ones in untreated or IFN patients, which could explain the less favorable treatments offered. Severe fibrosis/cirrhosis is broadly accepted as the pathogenetic mechanism for HCC development after SVR, with hundreds of publications available. However, the HCC development in the noncirrhotic liver after a cleared HCV infection is a reason for the discrepancy in expectations, particularly if it develops with multinodular or aggressive patterns, as detailed in some case reports published [34]. Since 2017, in Europe, DAA therapy has also been administered to the F0-F2 liver, in case of comorbidities. Although relatively less common (4.4-10.6\%), liver cancer arises in noncirrhotic and HCV-positive patients $[35,36]$. In these cases, its prognosis is generally better than in cirrhosis, especially if $\mathrm{HCC}$ is at an early stage when curative therapy, liver resection, or radiofrequency ablation can be performed. In our cohort, some HCV-cleared patients showing F0-F2 fibrosis with no alcohol abuse or severe metabolic syndrome developed HCC with an aggressive pattern. The combination of this evidence on liver fibrosis (sometimes low), liver function (acceptable), and tumor stage (frequently advanced in size, number, or vascular invasion) (Table 3) supports the hypothesis that different and not previously considered factors may lead to tumor outgrowth after DAA treatment. The interaction of HCV with its human host is complex and multilayered. HCC development is probably determined by several viral and host factors. Direct and indirect mechanisms of HCV-induced HCC include activation of multiple host pathways such as liver fibrogenic pathways, cellular and survival pathways, and interaction with the immune and metabolic systems. Host factors also play a major role in $\mathrm{HCV}$-induced $\mathrm{HCC}$, as evidenced by genomic studies identifying polymorphisms in immune, metabolic, and growth signaling systems associated with increased risk of HCC [37-39].

The hypothesis raised by researchers points at considering that the HCV elimination may open a temporary immunosuppressive phase that might determine the ideal conditions for the growth of dormant micronodules [40]. In support of the hypothesis of DAA-induced immunosuppression, there was evidence of an increase in reactivations of the hepatitis B virus and herpes viruses after the new DAA therapies [41,42]. Our data agree that the greatest incidence of HCC among DAA-treated patients was in the first months after $\mathrm{HCV}$ eradication; therefore, a leading role of the immune system in deter- 
mining rapid HCC evolution shall not be excluded. Patients treated with DAA shall be followed up strictly after HCC eradication, especially in the case of chronic HCV infection, considering that potentially transformed cells may proliferate in conditions of reduced immune surveillance.

Our study highlighted that HCC may develop in the noncirrhotic liver after SVR mediated by DAA treatment, sometimes showing more aggressive behavior. Unfortunately, this study has some limitations: first, it had a relatively short follow-up time as a consequence of the recent introduction of DAAs in Italy (2015), and further information about the HCC incidence after viral cure is still needed. Second, our patients had a diagnosis of HCV infection 15-30 years before the DAA regimen, and the development of HCC may be linked to the continuous viral damage also present in noncirrhotic patients. Since HCV-related HCC onset is time-dependent, this investigational hypothesis could suggest new studies comparing the onset of HCC in patients with a short-lasting HCV infection treated with DAAs. Third, it was not possible to introduce a control group that was not treated with antiviral therapy due to ethical restrictions. A further limitation is represented by the sample size of our population due to the fact that this is a single-center study.

\section{Conclusions}

Some aspects of the impact of DAA therapy on mechanisms of HCC onset are still debated. The previous case series considered cirrhosis as the driver of HCC development. Underground moderate fibrosis should induce the investigation of other pathophysiological mechanisms. HCV infection exposition-time and the immunological state after DAA therapy may play important roles. Our data suggest that DAA therapy should be prioritized in patients with newly diagnosed HCV infection in order to successfully prevent liver damage and HCC onset.

Data obtained from this limited cohort of patients have to be interpreted with caution, and larger numbers of patients have to be studied in order to identify the responsible pathway for HCC development in noncirrhotic patients achieving SVR.

The future is bright for HCV patients since newly diagnosed HCV patients have a short viral exposition due to the improved access to DAA therapy.

Supplementary Materials: The following are available online at https://www.mdpi.com/article/10 $.3390 /$ cancers13123025/s1, Table S1: Characteristics of the study population-younger than 65 years.

Author Contributions: Conceptualization, S.B. (Stefania Brozzetti) and S.B. (Simone Bini); data curation, G.M.D.S., C.F., P.L., M.D.M., M.B., and A.C.; formal analysis, V.C.M.; funding acquisition, S.B. (Stefania Brozzetti); investigation, M.D.M.; project administration, S.B. (Stefania Brozzetti); visualization, R.M.P.; writing-original draft, S.B. (Stefania Brozzetti), M.T., S.B. (Simone Bini), C.D.L., J.A., and C.D.; writing-review and editing, S.B. (Stefania Brozzetti), S.B. (Simone Bini), C.D.L., J.A., C.D., and R.M.P. All authors have read and agreed to the published version of the manuscript.

Funding: This research received no external funding; the APC was funded by Sapienza University of Rome.

Institutional Review Board Statement: Waived because of the retrospective nature of the study and the conventional procedures used.

Informed Consent Statement: Waived because of the retrospective nature of the study; all patients signed a privacy statement allowing the practitioners to manipulate their data.

Data Availability Statement: Available at request to the corresponding author.

Conflicts of Interest: The sponsors had no role in the design, execution, interpretation, or writing of the study. 


\section{References}

1. Sung, H.; Ferlay, J.; Siegel, R.L.; Laversanne, M.; Soerjomataram, I.; Jemal, A.; Bray, F. Global cancer statistics 2020: GLOBOCAN estimates of incidence and mortality worldwide for 36 cancers in 185 countries. CA Cancer J. Clin. 2021, 71, 209-249. [CrossRef]

2. World Health Organization, International Agency for Research on Cancer. GLOBOCAN 2020. Available online: http://globocan. iarc.fr (accessed on 15 April 2021).

3. Lanini, S.; Ustianowski, A.; Pisapia, R.; Zumla, A.; Ippolito, G. Viral Hepatitis: Etiology, Epidemiology, Transmission, Diagnostics, Treatment, and Prevention. Infect. Dis. Clin. N. Am. 2019, 33, 1045-1062. [CrossRef] [PubMed]

4. El-Serag, H.B. Hepatocellular carcinoma. N. Engl. J. Med. 2011, 365, 1118-1127. [CrossRef] [PubMed]

5. Kulik, L.; El-Serag, H.B. Epidemiology and Management of Hepatocellular Carcinoma. Gastroenterology 2019, $156,477-491$. [CrossRef] [PubMed]

6. $\quad$ Lok, A.S.; Seeff, L.B.; Morgan, T.R.; di Bisceglie, A.M.; Sterling, R.K.; Curto, T.M.; Everson, G.T.; Lindsay, K.L.; Lee, W.M.; Bonkovsky, H.L.; et al. Incidence of hepatocellular carcinoma and associated risk factors in hepatitis c-related advanced liver disease. Gastroenterology 2009, 136, 138-148. [CrossRef] [PubMed]

7. Cardoso, A.-C.; Moucari, R.; Figueiredo-Mendes, C.; Ripault, M.-P.; Giuily, N.; Castelnau, C.; Boyer, N.; Asselah, T.; MartinotPeignoux, M.; Maylin, S.; et al. Impact of peginterferon and ribavirin therapy on hepatocellular carcinoma: Incidence and survival in hepatitis C patients with advanced fibrosis. J. Hepatol. 2010, 52, 652-657. [CrossRef]

8. Coppola, N.; Pisaturo, M.; Tonziello, G.; Sagnelli, C.; Sagnelli, E.; Angelillo, I.F. Efficacy of pegylated interferon $\alpha$-2a and $\alpha$-2b in patients with genotype 1 chronic hepatitis C: A meta-analysis. BMC Infect. Dis. 2012, 12, 357. [CrossRef]

9. Wei, L.; Huang, Y.-H. Long-term outcomes in patients with chronic hepatitis $\mathrm{C}$ in the current era of direct-acting antiviral agents. Expert Rev. Anti-Infect. Ther. 2019, 17, 311-325. [CrossRef]

10. Carrat, F.; Fontaine, H.; Dorival, C.; Simony, M.; Diallo, A.; Hezode, C.; De Ledinghen, V.; Larrey, D.; Haour, G.; Bronowicki, J.-P.; et al. Clinical outcomes in patients with chronic hepatitis $\mathrm{C}$ after direct-acting antiviral treatment: A prospective cohort study. Lancet 2019, 393, 1453-1464. [CrossRef]

11. Registri AIFA Per il Monitoraggio Dei Farmaci Anti-HCV (Aggiornamento del 29 March 2021). Available online: https:/ /www. aifa.gov.it/aggiornamento-epatite-c (accessed on 20 April 2021).

12. Reig, M.; Mariño, Z.; Perelló, C.; Iñarrairaegui, M.; Ribeiro, A.; Lens, S.; Díaz, A.; Vilana, R.; Darnell, A.; Varela, M.; et al. Unexpected high rate of early tumor recurrence in patients with HCV-related HCC undergoing interferon-free therapy. J. Hepatol. 2016, 65, 719-726. [CrossRef]

13. Conti, F.; Buonfiglioli, F.; Scuteri, A.; Crespi, C.; Bolondi, L.; Caraceni, P.; Foschi, F.G.; Lenzi, M.; Mazzella, G.; Verucchi, G.; et al. Early occurrence and recurrence of hepatocellular carcinoma in HCV-related cirrhosis treated with direct-acting antivirals. J. Hepatol. 2016, 65, 727-733. [CrossRef]

14. Romano, A.; Angeli, P.; Piovesan, S.; Noventa, F.; Anastassopoulos, G.; Chemello, L.; Cavalletto, L.; Gambato, M.; Russo, F.P.; Burra, P.; et al. Newly diagnosed hepatocellular carcinoma in patients with advanced hepatitis C treated with DAAs: A prospective population study. J. Hepatol. 2018, 69, 345-352. [CrossRef]

15. Piñero, F.; Mendizabal, M.; Ridruejo, E.; Wolff, F.H.; Ameigeiras, B.; Anders, M.; Schinoni, M.I.; Reggiardo, V.; Palazzo, A.; Videla, M.; et al. Treatment with direct-acting antivirals for HCV decreases but does not eliminate the risk of hepatocellular carcinoma. Liver Int. 2019, 39, 1033-1043. [CrossRef]

16. Vallet-Pichard, A.; Mallet, V.; Nalpas, B.; Verkarre, V.; Nalpas, A.; Dhalluin-Venier, V.; Fontaine, H.; Pol, S. FIB-4: An inexpensive and accurate marker of fibrosis in HCV infection. comparison with liver biopsy and fibrotest. Hepatology 2007, 46, 32-36. [CrossRef]

17. Ioannou, G.N.; Beste, L.A.; Green, P.K.; Singal, A.G.; Tapper, E.B.; Waljee, A.K.; Sterling, R.K.; Feld, J.J.; Kaplan, D.E.; Taddei, T.H.; et al. Increased risk for hepatocellular carcinoma persists up to 10 years after hcv eradication in patients with baseline cirrhosis or high FIB-4 scores. Gastroenterology 2019, 157, 1264-1278.e4. [CrossRef]

18. Maurice, J.; Pinzani, M. The stratification of cirrhosis. Hepatol. Res. 2020, 50, 535-541. [CrossRef]

19. Pawlotsky, J.-M.; Negro, F.; Aghemo, A.; Berenguer, M.; Dalgard, O.; Dusheiko, G.; Marra, F.; Puoti, M.; Wedemeyer, H. EASL Recommendations on Treatment of Hepatitis C 2018. J. Hepatol. 2018, 69, 461-511. [CrossRef] [PubMed]

20. Llovet, J.M.; Brú, C.; Bruix, J. Prognosis of Hepatocellular Carcinoma: The BCLC Staging Classification. Semin. Liver Dis. 1999, 19, 329-338. [CrossRef] [PubMed]

21. Subramaniam, S.; Kelley, R.K.; Venook, A.P. A review of hepatocellular carcinoma (HCC) staging systems. Chin. Clin. Oncol. 2013, 2, 33. [CrossRef] [PubMed]

22. European Association for the Study of the Liver. Electronic address eee, European Association for the Study of the L. EASL Clinical Practice Guidelines: Management of hepatocellular carcinoma. J. Hepatol. 2018, 69, 182-236. [CrossRef] [PubMed]

23. Li, S.; Saviano, A.; Erstad, D.J.; Hoshida, Y.; Fuchs, B.C.; Baumert, T.; Tanabe, K.K. Risk Factors, Pathogenesis, and Strategies for Hepatocellular Carcinoma Prevention: Emphasis on Secondary Prevention and Its Translational Challenges. J. Clin. Med. 2020, 9, 3817. [CrossRef]

24. Hu, C.-C.; Weng, C.-H.; Hua, M.-C.; Chang, P.-H.; Lin, C.-L.; Chen, Y.-T.; Chien, C.-H.; Lin, S.-T.; Chien, R.-N. New Scoring Method to Predict Risk of Hepatocellular Carcinoma in Patients with Chronic Hepatitis C After Pegylated Interferon and Ribavirin Therapy. J. Interf. Cytokine Res. 2020, 40, 82-91. [CrossRef] 
25. Dash, S.; Aydin, Y.; Widmer, K.E.; Nayak, L. Hepatocellular Carcinoma Mechanisms Associated with Chronic HCV Infection and the Impact of Direct-Acting Antiviral Treatment. J. Hepatocell. Carcinoma 2020, 7, 45-76. [CrossRef] [PubMed]

26. Kozbial, K.; Moser, S.; Schwarzer, R.; Laferl, H.; Al-Zoairy, R.; Stauber, R.; Stättermayer, A.F.; Beinhardt, S.; Graziadei, I.; Freissmuth, C.; et al. Unexpected high incidence of hepatocellular carcinoma in cirrhotic patients with sustained virologic response following interferon-free direct-acting antiviral treatment. J. Hepatol. 2016, 65, 856-858. [CrossRef] [PubMed]

27. Cardoso, H.; Vale, A.M.; Rodrigues, S.; Gonçalves, R.; Albuquerque, A.; Pereira, P.; Lopes, S.; Silva, M.; Andrade, P.; Morais, R.; et al. High incidence of hepatocellular carcinoma following successful interferon-free antiviral therapy for hepatitis $C$ associated cirrhosis. J. Hepatol. 2016, 65, 1070-1071. [CrossRef] [PubMed]

28. Ravi, S.; Axley, P.; Jones, D.; Kodali, S.; Simpson, H.; McGuire, B.M.; Singal, A.K. Unusually High Rates of Hepatocellular Carcinoma After Treatment with Direct-Acting Antiviral Therapy for Hepatitis C Related Cirrhosis. Gastroenterology 2017, 152, 911-912. [CrossRef] [PubMed]

29. Mashiba, T.; Joko, K.; Kurosaki, M.; Ochi, H.; Osaki, Y.; Kojima, Y.; Nakata, R.; Goto, T.; Takehiro, A.; Kimura, H.; et al. Does interferon-free direct-acting antiviral therapy for hepatitis $\mathrm{C}$ after curative treatment for hepatocellular carcinoma lead to unexpected recurrences of HCC? A multicenter study by the Japanese Red Cross Hospital Liver Study Group. PLoS ONE 2018, 13, e0194704. [CrossRef]

30. Guarino, M.; Sessa, A.; Cossiga, V.; Morando, F.; Caporaso, N.; Morisco, F. Direct-acting antivirals and hepatocellular carcinoma in chronic hepatitis C: A few lights and many shadows. World J. Gastroenterol. 2018, 24, 2582-2595. [CrossRef]

31. Yamada, R.; Hiramatsu, N.; Oze, T.; Urabe, A.; Tahata, Y.; Morishita, N.; Kodama, T.; Hikita, H.; Sakamori, R.; Yakushijin, T.; et al. Incidence and risk factors of hepatocellular carcinoma change over time in patients with hepatitis $C$ virus infection who achieved sustained virologic response. Hepatol. Res. 2019, 49, 570-578. [CrossRef]

32. Issa, D.; Dessie, S.; Matherly, S. Unusually Aggressive Hepatocellular Carcinoma Developing After Treatment of Hepatitis C with Direct-Acting Antivirals. Am. J. Gastroenterol. 2017, 112, 1184-1185. [CrossRef]

33. El Fayoumie, M.; Abdelhady, M.; Gawish, A.; Hantour, U.; Abdelkhaleek, I.; Abdelraheem, M.; Alsawak, A.; Alwassief, A.; Elbahrawy, A. Changing Patterns of Hepatocellular Carcinoma after Treatment with Direct Antiviral Agents. Gastrointest. Tumors 2020, 7, 1-10. [CrossRef]

34. Brozzetti, S.; Bini, S.; Fazzi, K.; Chiarella, L.L.; Ceccarossi, V.; De Lucia, C.; De Toma, G. Case-report: Metastases in a low-stage middle-graded HCC in cleared HCV infection, non-cirrhotic liver: Surgical therapy. Int. J. Surg. Case Rep. 2018, 47, 19-21. [CrossRef] [PubMed]

35. Desai, A.; Sandhu, S.; Lai, J.-P.; Sandhu, D.S. Hepatocellular carcinoma in non-cirrhotic liver: A comprehensive review. World J. Hepatol. 2019, 11, 1-18. [CrossRef] [PubMed]

36. Yeh, M.M.; Daniel, H.D.-J.; Torbenson, M. Hepatitis C-associated hepatocellular carcinomas in non-cirrhotic livers. Mod. Pathol. 2009, 23, 276-283. [CrossRef]

37. Goossens, N.; Hoshida, Y. Hepatitis C virus-induced hepatocellular carcinoma. Clin. Mol. Hepatol. 2015, 21, 105-114. [CrossRef] [PubMed]

38. Shirvani-Dastgerdi, E.; Schwartz, R.E.; Ploss, A. Hepatocarcinogenesis associated with hepatitis B, delta and C viruses. Curr. Opin. Virol. 2016, 20,1-10. [CrossRef]

39. Liu, P.; Ge, M.; Hu, J.; Li, X.; Che, L.; Sun, K.; Cheng, L.; Huang, Y.; Pilo, M.G.; Cigliano, A.; et al. A functional mammalian target of rapamycin complex 1 signaling is indispensable for c-Myc-driven hepatocarcinogenesis. Hepatology 2017, 66, 167-181. [CrossRef] [PubMed]

40. Chu, P.-S.; Nakamoto, N.; Taniki, N.; Ojiro, K.; Amiya, T.; Makita, Y.; Murata, H.; Yamaguchi, A.; Shiba, S.; Miyake, R.; et al. On-treatment decrease of NKG2D correlates to early emergence of clinically evident hepatocellular carcinoma after interferon-free therapy for chronic hepatitis C. PLoS ONE 2017, 12, e0179096. [CrossRef] [PubMed]

41. Collins, J.M.; Raphael, K.L.; Terry, C.; Cartwright, E.J.; Pillai, A.A.; Anania, F.A.; Farley, M.M. Hepatitis B Virus Reactivation During Successful Treatment of Hepatitis C Virus with Sofosbuvir and Simeprevir. Clin. Infect. Dis. 2015, 61, 1304-1306. [CrossRef]

42. Fernández-Carrillo, C.; Londoño, M.-C.; Arias-Loste, T.; Hernández-Conde, M.; Llerena, S.; Crespo, J.; Forns, X.; Calleja, J.L. Reactivation of Herpesvirus in Patients with Hepatitis C Treated with Direct-Acting Antiviral Agents. Clin. Gastroenterol. Hepatol. 2016, 14, 1662-1666. [CrossRef] 